\title{
Immune differences in captive and free-ranging zebras (Equus zebra and E. quagga)
}

\author{
Peter A. Seeber ${ }^{1,6}\left(\mathbb{D} \cdot\right.$ Thomas Morrison $^{2} \cdot$ Alix Ortega $^{3} \cdot$ Marion L. East $^{4} \cdot$ Alex D. Greenwood $^{1,5} \cdot$ Gábor Á. Czirják $\mathbf{k}^{1}$ (I)
}

Received: 30 October 2019 / Accepted: 8 January 2020 / Published online: 2 March 2020

(c) The Author(s) 2020

\begin{abstract}
Wild mammals in ex situ captivity experience substantially different environmental conditions compared to free-ranging conspecifics, e.g., in terms of diet, climatic conditions, social factors, movement space, and direct anthropogenic disturbance. Moreover, animals in captivity frequently undergo management interventions such as medical treatments which may influence pathogen pressure. Captivity is known to affect immunological responses in some terrestrial and marine mammals; however, it is unclear whether this can be generalized to other taxa. Furthermore, little is known about how energetically costly life history stages such as lactation influence the immune system in wildlife. We measured expression of components of the constitutive and induced innate immunity and of the adaptive immune system in plains and mountain zebras (Equus quagga and $E$. zebra), including lactating and non-lactating individuals. As a proxy for general immune function, we screened for lytic equine herpesvirus (EHV) infection, a common and often latent pathogen which is reactivated in response to stress and immune challenge. Both energetically cheap markers of the constitutive innate immunity were lower in captive than in wild zebras, whereas energetically costly markers of the induced innate immunity were more highly expressed in captive zebras. Lactation was associated with higher titers of natural antibodies and lysozyme. Lytic EHV infection was not significantly correlated with any of the measured immune markers. Our results suggest that captivity and lactation may influence immune functions in zebra mares.
\end{abstract}

Keywords Adaptive immunity $\cdot$ Innate immunity $\cdot$ Captivity $\cdot$ Lactation $\cdot$ Equid herpesvirus

Handling editor: Raquel Monclús.

Peter A. Seeber

seeber.pa@gmail.com

1 Department of Wildlife Diseases, Leibniz Institute for Zoo and Wildlife Research, Alfred-Kowalke Str. 17, 10315 Berlin, Germany

2 Institute of Biodiversity, Animal Health and Comparative Medicine, University of Glasgow, G12 8QQ Glasgow, UK

3 Réserve Africaine de Sigean, 19 Chemin Hameau du Lac, RD, 6009, 11130 Sigean, France

4 Department of Ecological Dynamics, Leibniz Institute for Zoo and Wildlife Research, Alfred-Kowalke Str. 17, 10315 Berlin, Germany

5 Department of Veterinary Medicine, Freie Universität Berlin, Oertzenweg 19b, 14163 Berlin, Germany

6 Present Address: Limnological Institute, University of Konstanz, Mainaustr. 252, 78464 Konstanz, Germany

\section{Introduction}

Maintaining captive wildlife populations has become an important conservation strategy for many species (SchulteHostedde and Mastromonaco 2015). For some species, life in captivity is not detrimental, whereas it can have negative effects on well-being, health, and fecundity of others (Mellor et al. 2018). Negative impacts of captivity can strongly constrain the success of captive breeding programs (Mason 2010); therefore, for in situ and ex situ conservation strategies to be effective, knowledge on a species' physiological requirements and resilience is vital. Resistance to pathogens conferred by the immune system represents one of the most important physiological functions in long-lived animals, and various environmental factors are known to modulate immune functions (Bowden 2008; Buehler et al. 2008; Ewenson et al. 2001; Tung et al. 2012). Ex situ captivity reflects a substantial deviation from the natural environment for many free-ranging wildlife species, with key differences such as diet, climate, social factors, or movement space 
(Boyd 1986; Morgan and Tromborg 2007; Schulte-Hostedde and Mastromonaco 2015), all of which may affect immune functions. Moreover, anthropogenic interventions such as medical care and prophylaxes may affect pathogen pressure. Intestinal parasites, for example, are typically less abundant in captive animals due to prophylaxes and treatment schemes (Wambwa et al. 2004). The multiple differences between ex situ captivity and natural settings could be expected to alter immune functions.

Mammalian immunity is complex, and measuring any single immune marker is insufficient to draw conclusions on overall immune function (Ruoss et al. 2019). Furthermore, immune markers do not necessarily co-vary; therefore, it is vital to measure multiple components of the immune system (Heinrich et al. 2017; Lee 2006; Pap et al. 2010; Peck et al. 2016). In vertebrates, immune defense consists of two branches- the innate and the adaptive immune system. Innate immunity refers to immune functions that are non-specific and, thus, do not require previous exposure to a given pathogen; these unspecific responses to infection serve to eliminate and prevent spreading of potential pathogens within the organism, and to initiate an inflammatory response (Janeway et al. 2001). The innate immune system is subdivided into constitutive and induced responses. The constitutive factors such as lysozyme and natural antibodies are present without immediate exposure to pathogens (Janeway et al. 2001). Lysozyme is an integral part of antibacterial constitutive immunity and is, thus, an important biomarker of the innate immune response. Natural antibodies, which bind non-specifically to various antigens, have important roles in opsonization, and their concentration can rapidly increase following infection (Boes 2001). In equids, the majority of natural antibodies are accounted for by $\operatorname{IgM}$ (Borghesi et al. 2014). In contrast to constitutive innate immunity, the induced innate immune response (e.g., acute phase response) is only activated due to invading pathogens (Janeway et al. 2001). Acute phase proteins (APPs), such as haptoglobin and serum amyloid A (SAA), are vital components of the acute phase response in equids (Belgrave et al. 2013; Cray et al. 2009; Cray and Belgrave 2014); they are part of the early response of the innate immunity which is elicited by inflammation, infection, stress, or trauma. In contrast to innate immunity, adaptive immunity is characterized by highly specific antigen recognition that induces responses to pathogens that have been previously encountered (Janeway et al. 2001). Immunoglobulin $\mathrm{G}(\mathrm{IgG})$ is the most abundant circulating antibody serotype-it is the main effector of the humoral adaptive immunity and specifically binds antigens that are recognized upon initial exposure (Janeway et al. 2001).

Mounting an immune response can be energetically costly (Lee 2006) and can also involve immuno-pathological consequences, e.g., during inflammatory reactions (Lochmiller and Deerenberg 2014; Rauw 2012; Sandland and Minchella 2003). Constitutive innate immunity is typically associated with relatively low energetic cost (e.g., lysozyme and natural antibodies), whereas induced innate responses (e.g., APPs) entail higher energetic costs (Rauw 2012). There is evidence that in various animal species, an increase in energetic costs elsewhere (e.g., investment in growth or reproduction) may lead to a trade-off in terms of reduced immunity (French et al. 2007; Lee 2006; Peck et al. 2016; Sandland and Minchella 2003). Several studies on various mammalian species reported increasing parasite loads during lactation, which is likely due to a down-regulation of the immune system as a consequence of increased energy expenditure due to milk production (East et al. 2015; Lloyd 1983; Sheldon and Verhulst 1996). In contrast to this assumed general down-regulation of immunity, lactation also serves as passive immunization of the offspring via the milk (Borghesi et al. 2014; Moffett and Loke 2006) and has been shown to be associated with increased expression of certain adaptive and innate immune markers such as $\mathrm{IgG}$, haptoglobin, and lysozyme (Budzyńska 2002; Veronesi et al. 2014).

Numerous studies have been performed on the immune function of captive animals. However, the results are not necessarily generalizable to free-ranging conspecifics (Pedersen and Babayan 2011; Tian et al. 2015). For example, the immune system of free-ranging rodents is more active (e.g., higher immunoglobulin levels) and more antigenexperienced (e.g., higher effector than naïve lymphocytes) than that of laboratory rodents (reviewed in Viney and Riley 2017). In contrast, proliferative and cytokine responses are typically lower in wild rodents (reviewed in Viney and Riley 2017). Species with different life histories invest differently in homeostasis (e.g., immune function, stress response; Pap et al. 2015), and therefore, more pronounced differences in captivity-associated immune phenotype may be predicted for large mammals, compared to small rodents. To our knowledge, only two studies have compared the immune functions of captive large mammals with free-ranging individuals. Flies et al. (2015) showed that in spotted hyenas (Crocuta crocuta), the concentrations of certain immunoglobulins (IgG, IgM, and natural and auto-antibodies) were significantly lower in captive than wild individuals, whereas no difference was observed in the overall function of the constitutive innate immunity measured by the bacterial killing capacity of the serum. Common bottlenose dolphins (Tursiops truncatus) also showed that various immune markers (e.g., IgG, lysozyme, and cytokines) were less expressed in captive than in free ranging animals (Fair et al. 2017), whereas major APPs were variably expressed (Cray et al. 2013). These results suggest that the elevated immune response in free-ranging wildlife reflects higher exposure to pathogens; however, further studies in other mammal species are needed to understand the physiological requirements 
and resilience of animals in in situ and ex situ conservation programs.

The objective of this study was to compare expression of several immune markers between free-living and captive zebras. Furthermore, we compared these markers between lactating and non-lactating zebra mares, as the energetic costs of lactation may affect immune functions. We measured concentrations of these immune markers in free-ranging zebra mares from two African national parks and in mares held in ex situ captivity (European zoos). The measured immune factors included two markers of the constitutive innate immune system (natural antibodies and lysozyme, which are considered energetically cheap), two markers of induced innate immunity (haptoglobin and SAA, which are energetically costly), and one marker of the adaptive immune response (total $\mathrm{IgG}$ ). Furthermore, during acute infection, immunosuppression or acute stress, latent viruses such as herpesviruses are often reactivated (Marenzoni et al. 2015; Seeber et al. 2018a; White et al. 2012); therefore, this opportunistic re-activation of otherwise latent viral infections, termed lytic infection, may be associated with a decrease in general immunocompetence in latently infected organisms. We screened for lytic equine herpesvirus (EHV) infections and assessed seroprevalence of specific antibodies against two clinically important strains (EHV-1, and EHV-9) using a peptide-based enzyme-linked immunosorbent assay ([ELISA]; Abdelgawad et al. 2015).

\section{Materials and methods}

\section{Sample collection}

Blood samples were collected from wild mountain zebras (Equus zebra) and plains zebras (E. quagga) in Etosha National Park, Namibia, in December 2015, and from plains zebras in Serengeti National Park, Tanzania, from the end of May to the end of June 2016 (Table 1). This corresponded to the late dry season in Namibia, and the early dry season in Tanzania. All wild animals sampled were adult mares $(N=29)$ that were categorized by their reproductive state as either lactating (when mares had a suckling foal at foot,

Table 1 Distribution of samples by zebra species, environment, and geographical origin (site)

\begin{tabular}{lllr}
\hline Species & Environment & Site & $N$ \\
\hline Plains zebra & Natural & Namibia & 5 \\
& & Tanzania & 17 \\
& Captive & Zoos (Europe) & 11 \\
Mountain zebra & Natural & Namibia & 7 \\
& Captive & Zoos (Europe) & 11 \\
\hline
\end{tabular}

$N=8)$ or non-lactating $(N=21)$. Lactating zebras were only sampled in Tanzania, and their foals were estimated to be between several weeks and 6 months of age, based on body size (Seeber et al. 2018b). Zebras were immobilized using a dart gun [as described by Costantini et al. (2018)]; blood samples were drawn from the jugular vein approximately 15-30 min after darting and were collected in serum or EDTA tubes (S-Monovette Z, and S-Monovette K, respectively, Sarstedt, Hildesheim, Germany). Serum was separated from the clot after 15-30 min and placed in cryotubes. To screen for acute lytic EHV infection, we collected nasal swabs and blood samples for extraction of viral DNA. In the field, all samples were transported in a cooling box on ice packs and were then stored at $-20{ }^{\circ} \mathrm{C}$ until transported to the Leibniz Institute for Zoo and Wildlife Research where they were stored at $-80^{\circ} \mathrm{C}$ until analysis.

Blood of captive adult female zebras was collected from plains and mountain zebras kept at four different zoological collections in Europe (Réserve Africaine de Sigean, France; Zoo Antwerp, Netherlands; Zoo Landau, Germany; and Givskud Zoo, Denmark). Blood, serum, and swab sampling were performed as described for wild animals. Captive zebras comprised 22 non-lactating mares (11 of each species; Table 1). No clinical signs of acute disease were observed in any of the captive or wild zebras.

\section{Hemagglutination assay}

Hemagglutination is characterized by the appearance of clumped red blood cells due to natural antibodies binding multiple antigens. Hemagglutination was measured in 96-well microtiter plates as described by Heinrich et al. (2017). Briefly, samples were serially diluted from 1:1 to $1: 1,024$ in PBS; $25 \mu \mathrm{L}$ of $1 \%$ chicken red blood cells suspension was added; and then plates were vortexed and incubated at $37{ }^{\circ} \mathrm{C}$ for $90 \mathrm{~min}$. After incubation, plates were tilted at a $45^{\circ}$ angle to increase the visualization of agglutination and kept at room temperature for 20 min until measurement. Natural antibody titers are presented as the $\log _{2}$ of the reciprocal of the highest dilution (i.e., lowest concentration) of serum showing positive hemagglutination.

\section{Lysozyme assay}

To measure lysozyme concentration, a lysoplate assay was used (Heinrich et al. 2017): $25 \mu \mathrm{L}$ plasma was inoculated in the test holes of a 1\% Noble agar gel (Sigma Aldrich; \# A5431-250G) containing $50 \mathrm{mg} / 100 \mathrm{~mL}$ lyophilized Micrococcus lysodeikticus (Sigma Aldrich; \# M3770-5G), a bacteria that is particularly sensitive to lysozyme concentration. Crystalline hen egg white lysozyme (Sigma Aldrich; \# L6876; dilutions: 0.75, 1, 2, 3, 5, 7.5, 10, 15, and $30 \mu \mathrm{g} / \mathrm{mL}$ ) was used to prepare a standard curve on 
each plate. Plates were incubated at room temperature $\left(25-27{ }^{\circ} \mathrm{C}\right)$ for $20 \mathrm{~h}$. During this period, as a result of bacterial lysis, a clear zone developed in the area of the gel surrounding the sample inoculation site. The diameters of the cleared zones are proportional to the logarithm of the lysozyme concentration. This area was measured three times digitally using the software ImageJ (version 1.48, http://imagej.nih.gov/ij/), and the mean was converted on a semi-logarithmic plot into hen egg lysozyme equivalents (in $\mu \mathrm{g} / \mathrm{mL}$ ) according to the standard curve (Rowe et al. 2013).

\section{Haptoglobin assay}

Haptoglobin concentrations were measured using a commercial kit (Tridelta Developments Ltd. distributed by Biorepair $\mathrm{GmbH}$; \#BR220) following the manufacturer's instructions. Haptoglobin concentrations $(\mathrm{mg} / \mathrm{mL})$ in plasma samples were calculated according to the standard curve on each plate.

\section{SAA assay}

SAA concentrations were measured using a commercial solid phase sandwich SAA Multispecies ELISA kit (Tridelta Developments Ltd. sold by Biorepair GmbH; \# BR230), following the manufacturer's instructions. Serum samples were initially diluted 1:2,000 as per recommendation of the manufacturer for measuring horse samples, or higher when SAA concentrations were above the measurement range (up to $1: 16,000)$. The absorbance of the ELISA was measured with a standard spectrophotometer (Biotek; $\mu$ Quant Microplate Spectrophotometer) and SAA concentrations were calculated according to the standard curve on each plate. Most samples ranged from 111.71 to $381,630.7 \mathrm{ng} / \mathrm{mL}$, however, in several samples $(N=9)$, SAA concentrations were too high for accurate measurement; these samples were assigned a maximum value $(500,000 \mathrm{ng} / \mathrm{mL})$ for statistical analyses. Several other samples $(N=25)$ produced SAA concentrations too low for accurate measurement at the initial dilution; thus, an absolute minimum value $(1 \mathrm{ng} / \mathrm{mL})$ was assigned to these samples in the statistical analyses.

\section{IgG assay}

A commercially available highly sensitive two-site ELISA kit (Abnova, \# KA2036) was used to quantify total IgG in serum. IgG concentration was determined by comparing measurements to a standard curve and adjusting for the dilution factor $(1: 200,000)$.

\section{Detection of EHV antibodies}

To investigate previous exposure to two of the most common equid alpha-herpesviruses, a peptide-based ELISA was employed for measuring EHV-1- and EHV-9-specific antibody titers, as described by Abdelgawad et al. (2015). Each serum sample was measured four times in total to assess mean antibody titers.

\section{Lytic EHV infections}

DNA was extracted from whole blood samples and nasal swabs using a commercially available kit (NucleoSpin Tissue, Macherey-Nagel, Düren, Germany) according to the manufacturer's instructions for the respective substrate (blood or buccal swab protocol, respectively). To test for lytic EHV infections, a nested PCR was performed as described by Kleiboeker et al. (2016) but using a modified thermocycling protocol (Seeber et al. 2017). Amplified products were visualized on an agarose gel (1.5\%) and were purified using a kit (NucleoSpin Gel and PCR Clean-up, Macherey-Nagel, Düren, Germany) according to manufacturer instructions for subsequent Sanger sequencing. Purified PCR products were sequenced by LGC Genomics $\mathrm{GmbH}$, Berlin, Germany, and virus strains were identified in GenBank (Benson et al. 2009) databases using BLAST searches. Zebras were considered to be in a state of lytic EHV infection when at least one of the samples (blood or nasal swab) was EHV positive.

\section{Statistical analyses}

A linear model was fitted for each immune marker as a response variable (natural antibody titer, lysozyme, and IgG concentrations, and log-transformed haptoglobin and $\log (x+1)$-transformed SAA concentrations) with the following predictors: sampling site (Namibia, Tanzania, or ex situ captivity), reproductive state (lactating or non-lactating), lytic EHV infection (positive or negative PCR result), and species (plains or mountain zebra). Visual inspections of residual distributions and quantile-quantile plots of the models indicated no obvious violation of assumptions of normality and homogeneity of error variances. Variance inflation factors were calculated using the package "car" (Fox and Weisberg 2011) and were $\leq 2.6$, suggesting no problem of multicollinearity in any of the models. To assess the statistical significance of the predictor variables we used F-tests to compare the full model to reduced models in which the respective predictor was removed. Significant differences between predictor variables were analyzed post hoc by a Tukey's Multiple Comparison of Means test. The difference in EHV-1 and EHV-9 seroprevalence between wild and captive animals was tested using a Fisher's exact test. 
No significant differences among zoos for any marker were observed using a Kruskal-Wallis test. Statistical analyses were performed using $\mathrm{R}$ version 3.2.5 (R Development Core Team 2016) and using the "multcomp" package (Hothorn et al. 2008) for post hoc tests. Statistical significance is reported at an $\alpha$-level of $p<0.05$.

\section{Ethical standards}

This study was approved by the Internal Committee for Ethics and Animal Welfare of the Leibniz-Institute for Zoo and Wildlife Research, approval number 2016-09-03. All protocols adhered to the laws and guidelines of Namibia, Tanzania, and Germany, respectively. Sampling in Namibia and Tanzania was performed with permission of the Environment and Tourism (permit No. 2094/2016), and the Tanzania Commission for Science and Technology (permit No. 2015-168-NA-90-130), respectively. Research in Tanzania was conducted with the support of the Tanzania Wildlife Research Institute and Tanzanian National Parks Authority. Permission to export sample material from Namibia was granted by an MET export permit (No. 105336), and from Tanzania by the Tanzania Wildlife Research Institute. Samples were transported to Germany in full compliance with the Convention on International Trade in Endangered Species (permit no. 108448) and in compliance with the Nagoya Protocol on Access to Genetic Resources.

\section{Results}

Mean values \pm standard deviation of the measured immune markers in wild and captive lactating and non-lactating plains zebras and in wild and captive mountain zebras are shown in Table 2. Natural antibody titers and lysozyme concentrations were higher in free-ranging zebras than in captive animals, whereas haptoglobin concentrations were higher in captive zebras (Tables 2,3). SAA concentrations were significantly higher in captive animals compared to Namibian zebras (Tables 3, 4; Fig. 1). IgG was not affected by any of the predictors (Table 3 ). No differences between zebra species were observed, apart from SAA, which was higher, on average, in plains zebras (mean 106,098 $\pm 201,537 \mathrm{ng} / \mathrm{mL}$ ) than in mountain zebras (mean $4498 \pm 10,910$; Tables 2,3 ).

Lactating zebras showed higher concentrations of constitutive innate markers (lysozyme and natural antibodies) than non-lactating zebras (Table 2; Fig. 2). Neither haptoglobin nor SAA was significantly different between lactating and non-lactating animals (Table 3 ).

The prevalence of lytic EHV infection as confirmed by PCR detection was similar in captive and wild animals (64\% and $62 \%$, respectively). Most EHVs belonged to the gammaherpesviruses (90\%); active alpha-herpesvirus infections

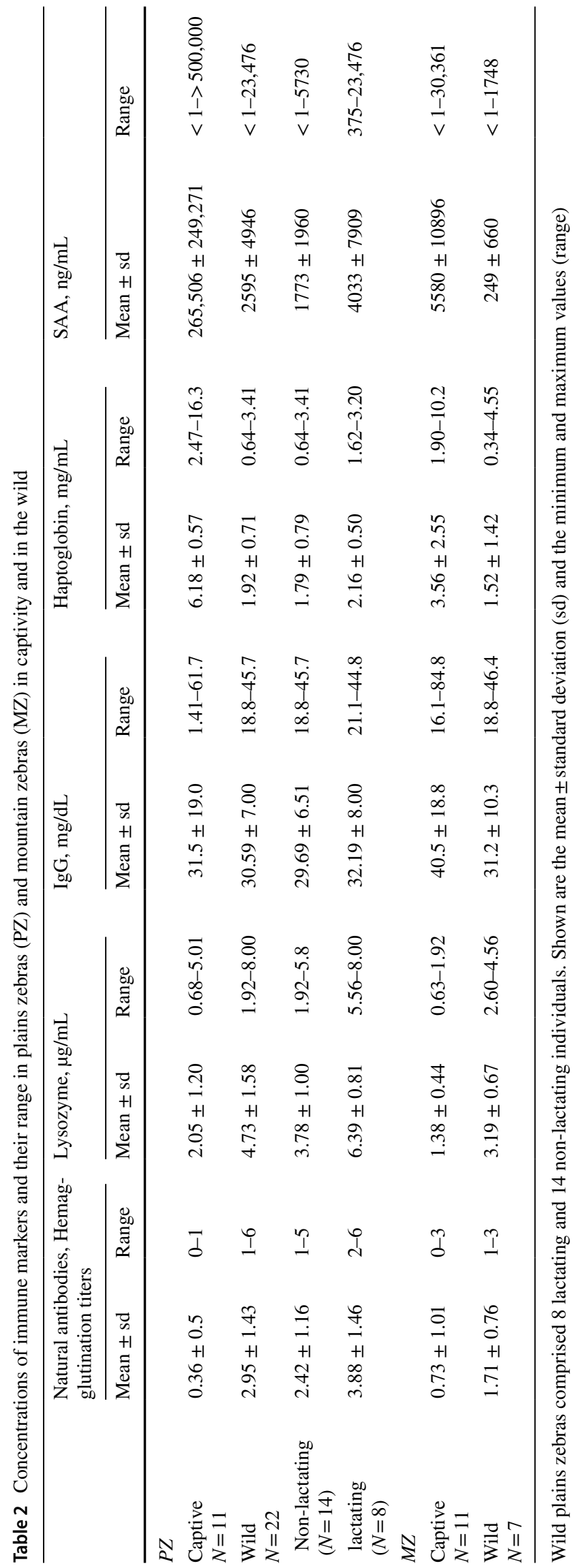


Table 3 Differences in the five immune markers regarding sampling site (Namibia, Tanzania, or ex situ captivity), lactation, lytic EHV infection, and species

\begin{tabular}{llrrr}
\hline Response & Predictor & Df & \multicolumn{1}{c}{$F$} \\
\hline Natural antibodies & Site & 2 & $\mathbf{1 4 . 8}$ & $<\mathbf{0 . 0 0 1}$ \\
& Lactation & 1 & $\mathbf{5 . 5}$ & $\mathbf{0 . 0 2 4}$ \\
& Lytic EHV infection & 1 & 0.3 & 0.581 \\
& Species & 1 & 0.2 & 0.694 \\
Lysozyme & Site & 2 & $\mathbf{2 2 . 9}$ & $<\mathbf{0 . 0 0 1}$ \\
& Lactation & 1 & $\mathbf{2 7 . 3}$ & $<\mathbf{0 . 0 0 1}$ \\
& Lytic EHV infection & 1 & 0.1 & 0.767 \\
IgG & Species & 1 & 1.89 & 0.176 \\
& Site & 2 & 1.5 & 0.228 \\
Haptoglobin & Lactation & 1 & 0.0 & 0.877 \\
& Lytic EHV infection & 1 & 0.7 & 0.402 \\
& Species & 1 & 3.1 & 0.086 \\
& Site & 2 & $\mathbf{1 3 . 1}$ & $<\mathbf{0 . 0 0 1}$ \\
& Lactation & 1 & 1.2 & 0.301 \\
SAA & Lytic EHV infection & 1 & 3.4 & 0.071 \\
& Species & 1 & 1.7 & 0.192 \\
& Site & 2 & $\mathbf{7 . 9}$ & $<\mathbf{0 . 0 0 1}$ \\
& Lactation & 1 & 0.1 & 0.764 \\
& Lytic EHV infection & 1 & 0.2 & 0.663 \\
& Species & 1 & $\mathbf{1 0 . 2 8}$ & $\mathbf{0 . 0 0 3}$ \\
\hline
\end{tabular}

Haptoglobin was log-transformed, and SAA concentrations were $\log (x+1)$-transformed

Significant effects in bold (at $p<0.05$ )

included EHV-9 $(N=2)$ and EHV-1 $(N=1)$. Lytic EHV infection as detected by PCR, however, was not a significant predictor of any of the immune markers tested (Table 3). Applying the peptide-based antigen ELISA, the prevalence of EHV-1 and EHV-9 was higher in wild than in captive animals: EHV-1-specific antibodies were detected in 50\% of captive and in $97 \%$ of wild zebras $(p<0.001)$ and EHV9 -specific antibodies in $5 \%$ of captive and in $90 \%$ of wild zebras $(p<0.001)$.

\section{Discussion}

Due to the complexity of the mammalian immune system, it is necessary to measure various components representing all branches to draw conclusions on overall immune competence (Ruoss et al. 2019). With this study, we provide reference values of five immune markers in two zebra species, measured in individuals in their natural habitats and in ex situ captivity. Constitutive and induced innate immune markers differed significantly between captive and free-ranging zebras, which is in line with previous immunological studies reporting that the immune system of free ranging animals is more active compared to that of captive conspecifics (Fair et al. 2017; Flies et al. 2015; Viney and Riley 2017). This may be due to higher levels of pathogen exposure in free-living animals. No differences were observed between environments in the adaptive immunity marker IgG. However, the sample sizes in the current study were small, and lactation is a confounding variable. Therefore, a larger sample size may be necessary to determine potential effects of captivity on adaptive immunity.

Both markers of constitutive innate immunity (natural antibody titers and lysozyme concentrations) were lower in zebras in ex situ captivity than in free-ranging individuals; however, the specific physiological or environmental factor driving these differences could not be identified in this study. Infection pressure, diet, and stress are among the most prominent factors shaping immune function (Martin et al. 2006). In wildlife husbandry, disease prevention (e.g., vaccination) and parasite control constitute major management efforts (e.g., lower intestinal
Table 4 Differences in immune markers between sampling sites, tested using a Tukey's multiple comparison of means

\begin{tabular}{llccrr}
\hline Response & Site & Estimate & Std. error & $t$ & \multicolumn{1}{c}{$t$} \\
\hline Natural antibodies & Zoo $\rightarrow$ Namibia & 1.29 & 0.37 & 3.47 & $\mathbf{0 . 0 0 3}$ \\
& Zoo $\rightarrow$ Tanzania & 2.20 & 0.44 & 4.96 & $<\mathbf{0 . 0 0 1}$ \\
& Namibia $\rightarrow$ Tanzania & 0.92 & 0.50 & 1.84 & 0.163 \\
Lysozyme & Zoo $\rightarrow$ Namibia & 1.48 & 0.31 & 4.73 & $<\mathbf{0 . 0 0 1}$ \\
& Zoo $\rightarrow$ Tanzania & 2.23 & 0.38 & 5.91 & $<\mathbf{0 . 0 0 1}$ \\
Haptoglobin & Namibia $\rightarrow$ Tanzania & 0.74 & 0.42 & 1.75 & 0.194 \\
& Zoo $\rightarrow$ Namibia & -1.17 & 0.25 & -4.73 & $<\mathbf{0 . 0 0 1}$ \\
& Zoo $\rightarrow$ Tanzania & -0.92 & 0.29 & -3.19 & $\mathbf{0 . 0 0 6}$ \\
SAA & Namibia $\rightarrow$ Tanzania & 0.25 & 0.32 & 0.77 & 0.722 \\
& Zoo $\rightarrow$ Namibia & -5.16 & 1.31 & -3.92 & $<\mathbf{0 . 0 0 1}$ \\
& Zoo $\rightarrow$ Tanzania & -2.44 & 1.58 & -1.55 & 0.275 \\
& Namibia $\rightarrow$ Tanzania & 2.72 & 1.78 & 1.54 & 0.279 \\
\hline
\end{tabular}

Haptoglobin was $\log$-transformed and SAA concentrations were $\log (\mathrm{x}+1)$-transformed. Significant effects in bold (at $p<0.05$ ) 

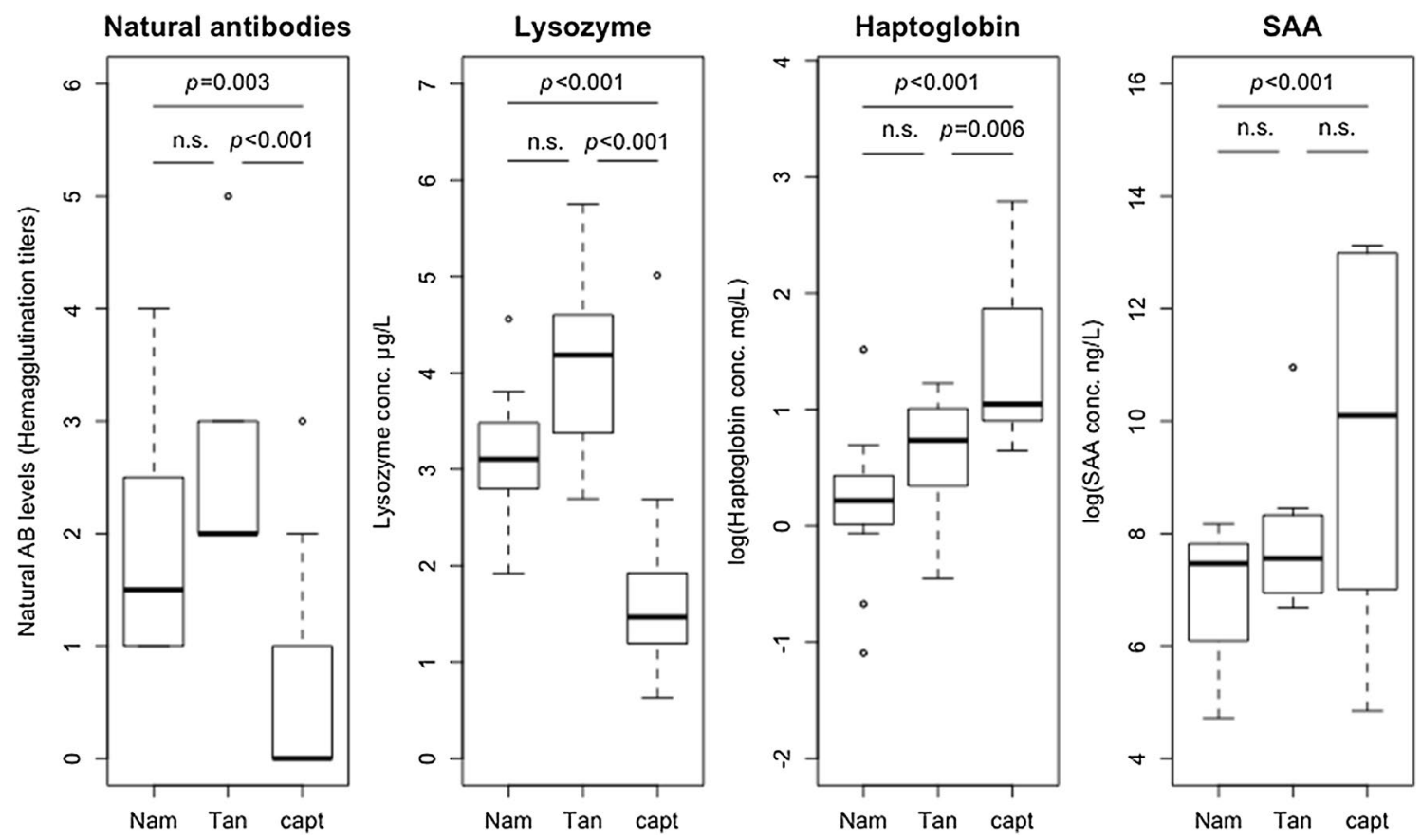

Fig. 1 Innate immune markers in non-lactating zebra mares in three environments. Nam: Namibia $(N=12)$; Tan: Tanzania $(N=9)$; capt: ex situ captivity $(N=38)$; boxes indicate 1 st and 3 rd quartiles, center lines indicate median values, upper (and lower) whiskers extend to
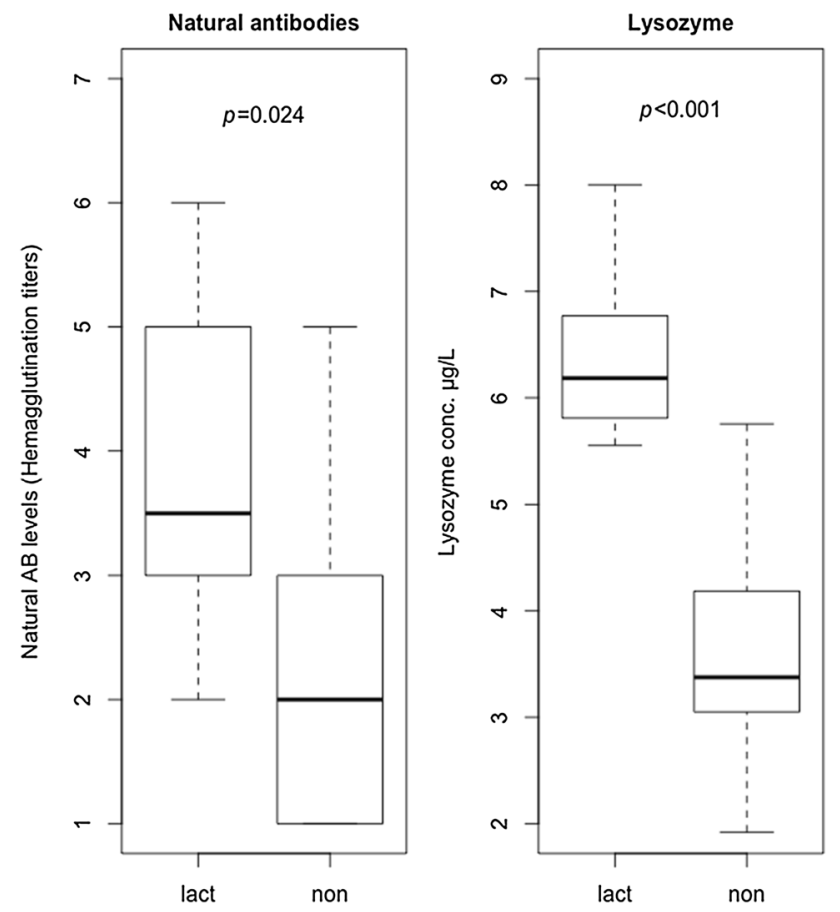

Fig. 2 Natural antibodies and lysozyme concentrations in free-ranging zebra mares that were either lactating or non-lactating. Lact: lactating $(N=8)$; non: non-lactating $(N=21)$. Boxes indicate 1st and 3rd quartiles, center lines indicate median values, upper (and lower) whiskers extend to the highest (and lowest) value that is within 1.5 times the inter-quartile range. Data points beyond the end of the whiskers are plotted as open dots. The p-values refer to the respective post hoc tests on the complete data set

the highest (and lowest) value that is within 1.5 times the inter-quartile range. Data points beyond the end of the whiskers are plotted as open dots. The $p$ values refer to the respective post hoc tests on the complete data set

parasite burden in captive than in free-ranging plains zebras; Wambwa et al. 2004), which reduces infection pressure. Furthermore, smaller population sizes and species diversity and resulting lower contact rates in captive zebras should result in lower pathogen transmission rates, which would further explain reduced investment in constitutive innate immunity. The plains zebra population of the Serengeti ecosystem is substantially larger than the mountain zebra population in Etosha National Park (IUCN 2017)—-the frequency of pathogen transmission likely increases with population density, which may, therefore, also explain higher constitutive immune markers in Tanzanian zebras compared to Namibian zebras.

In contrast to constitutive innate immunity, serum concentrations of induced innate immune markers were higher in captive than in wild zebras. The energetic costs of constitutive innate immunity are generally considered low, whereas the two measured markers of induced innate immunity are energetically costly (Lee 2006). In free-ranging wildlife (seasonal), nutrient shortages may result in energy deficiency and subsequent down-regulation of energetically costly immune factors, e.g., APPs (Sandland and Minchella 2003). Wildlife in captivity typically do not suffer from (seasonal) shortages of macronutrients, and the lack of energetic constraints would, therefore, not restrict the activation of more costly immune factors (Ewenson et al. 2001). Free-ranging zebras were sampled in different climatic and 
vegetation zones and during different seasons (in the late dry season in Namibia and in the early dry season in Tanzania); more adequate nutrient supply in the early than in the late dry season may also explain the intermediate levels in acute phase proteins in zebra mares from the Serengeti ecosystem, relative to zebras in Namibia and in captivity, even though all zebras in the wild exhibited good body condition.

Acute phase protein (haptoglobin and SAA) concentrations were generally higher in captive than in wild zebras. Concentrations of APPs can increase rapidly (by up to three orders of magnitude) during an inflammatory response or in response to a short-term stressor (Heinrich et al. 2017; Pepys et al. 1989). It may be difficult to interpret their concentrations as single-point measurements rather than taking measuring over time. However, elevated APP concentrations typically indicate inflammatory processes, and chronic stress in captive environments associated with exposure to adverse stimuli and limited space and puts captive animals at risk of chronic inflammation (Boyd 1986; Mason 2010; SchulteHostedde and Mastromonaco 2015), which may be another factor stimulating APP expression.

Budzyńska (2002) showed that in domestic horses, immune factors such as IgG, haptoglobin and lysozyme, increase significantly during late pregnancy and lactation. The epitheliochorial placenta of equids prevents intra-uterine passage of antibodies from mother to fetus; therefore, passive immunity transfer from mother to foal by colostrum is vital (Borghesi et al. 2014; Moffett and Loke 2006). The two constitutive immune markers (natural antibody and lysozyme concentrations) were significantly higher in lactating zebra mares than in non-lactating animals, whereas no differences in other immune markers were observed. However, a larger sample size may be required to assess potential effects of lactation in general. In equids, colostrum is produced within the last 2 weeks of pregnancy and contains antibodies such as IgG and $\operatorname{IgM}$, the concentrations of which decline rapidly by $24 \mathrm{~h}$ post-partum (Acworth 2010; Veronesi et al. 2014). Absorption of maternal specific and natural antibodies by the foal's intestinal epithelial cells is also only effective within about $32 \mathrm{~h}$ post-partum (Acworth, 2010); therefore, the effect of lactation on serum antibodies is likely limited to a comparably narrow time window. The mares that were considered lactating in the present study had foals of an estimated age of up to 6 months, which may explain why no effect of lactation serum IgG was found. It has been shown that several domestic mammals and laboratory animals have higher parasite loads during late pregnancy and lactation (East et al. 2015; Lloyd 1983). The significantly higher natural antibody titers we found in lactating mares likely reflect the mares' active immune response, rather than an up-regulation for passive immunization of the foals. In contrast to antibodies, other immune-related compounds such as lysozyme in milk can still have a protective effect during later stages of a foal's life
(Veronesi et al. 2014). Thus, up-regulation of these compounds should be detectable longer than antibodies during lactation, which was supported by our results.

Equine herpesviruses are endemic in equid populations throughout the world, with prevalences of over $90 \%$, depending on the EHV strain (Ataseven et al. 2009; Barnard and Paweska 1993; Borchers and Frölich 1997; Ehlers et al. 1999; Guevara et al. 2018; Seeber et al. 2019). Contrary to our expectations, lytic EHV infection was not a significant predictor for general immune function and, thus, might not function as a proxy measure of general immune function in zebras. A primary herpesvirus infection would be expected to elicit increased IgG titers (Svansson et al. 2009); however, no significant effect of virus status on IgG titers was found. Thus EHV-positive animals may not have been primarily infected, but instead may have undergone EHV reactivation and, therefore, not experienced significant activation of immunity. Consistent with previous studies such as Abdelgawad et al. (2015), significantly higher prevalence of EHV-1 and EHV-9 infection was found in wild zebras, compared to captive individuals. This result provides further support for lower infection pressure in the captive environment. EHV reactivation may not trigger a strong immune reaction, and the high prevalence may indicate a long-term accommodation between virus and host that is not strongly influenced by captivity.

\section{Conclusions}

Our results suggest that both ex situ captivity and lactation affect distinct aspects of the immune system in zebra mares. Both energetically inexpensive markers of the constitutive innate immunity were lower in captive than in wild zebras, whereas energetically costly markers of the induced innate immunity were more highly expressed in captive zebras. Lactation was associated with higher titers of natural antibodies and lysozyme. Lytic EHV infection was not significantly correlated with any of the measured immune markers. Further research is needed to identify the factors (and possible interactions between them) that cause the observed differences. A comprehensive understanding of environmental effects on immune function may result in better individual health outcomes and reproductive success of wild equids in captive environments.

Acknowledgements Open Access funding provided by Projekt DEAL. We thank the Ministry of Environment and Tourism, Namibia, the Tanzania Commission of Science and Technology, Tanzania National Parks and the Tanzania Wildlife Research Institute for permission to conduct research in the respective National Park. For assistance in Namibia we thank Jörg Melzheimer, Ruben Portas, Cheri Morkel, Dirk Bockmühl, Rebekka Müller, and Kenneth Uiseb. For assistance in Tanzania we thank Robert Fyumagwa, Ernest Eblate Mjingo, Maulid Luziga, and Grant Hopcraft. Our gratitude to Francis Vercammen of Zoo Antwerp, Jannis Göttling of Landau Zoo, and Ditte-Mari Sandgreen of Givskud Zoo for providing samples. We are grateful to Katja Pohle and Karin 
Hönig for assistance in the lab, and to the Institute of Poultry Diseases at the Freie Universität Berlin for providing chicken blood.

Funding This study was funded by a grant from the Leibniz Gemeinschaft [SAW-2015-IZW-1 440] and by the Leibniz Institute for Zoo and Wildlife Research.

\section{Compliance with ethical standards}

\section{Conflict of interests None.}

Open Access This article is licensed under a Creative Commons Attribution 4.0 International License, which permits use, sharing, adaptation, distribution and reproduction in any medium or format, as long as you give appropriate credit to the original author(s) and the source, provide a link to the Creative Commons licence, and indicate if changes were made. The images or other third party material in this article are included in the article's Creative Commons licence, unless indicated otherwise in a credit line to the material. If material is not included in the article's Creative Commons licence and your intended use is not permitted by statutory regulation or exceeds the permitted use, you will need to obtain permission directly from the copyright holder. To view a copy of this licence, visit http://creativecommons.org/licenses/by/4.0/.

\section{References}

Abdelgawad A, Hermes R, Damiani A, Lamglait B, Czirják GÁ, East M, Aschenborn O, Wenker C, Kasem S, Osterrieder N, Greenwood AD (2015) Comprehensive serology based on a peptide ELISA to assess the prevalence of closely related equine herpesviruses in zoo and wild animals. PLoS One 10:e0138370. https:// doi.org/10.1371/journal.pone. 0138370

Acworth NRJ (2010) The healthy neonatal foal: routine examinations and preventative medicine. Equine Vet Educ 15:45-49. https:// doi.org/10.1111/j.2042-3292.2003.tb01813.x

Ataseven VS, Dağalp SB, Güzel M, Başaran Z, Tan MT, Geraghty B (2009) Prevalence of equine herpesvirus- 1 and equine herpesvirus-4 infections in equidae species in Turkey as determined by ELISA and multiplex nested PCR. Res Vet Sci 86:339-344. https ://doi.org/10.1016/j.rvsc.2008.06.001

Barnard BJ, Paweska JT (1993) Prevalence of antibodies against some equine viruses in zebra (Zebra burchelli) in the Kruger National Park, 1991-1992. Onderstepoort J Vet Res 60:175-179

Belgrave RL, Dickey MM, Arheart KL, Cray C (2013) Assessment of serum amyloid A testing of horses and its clinical application in a specialized equine practice. J Am Vet Med Assoc 243:113-119. https://doi.org/10.2460/javma.243.1.113

Benson DA, Karsch-Mizrachi I, Lipman DJ, Ostell J, Sayers EW (2009) GenBank. Nucleic Acids Res 37(Database):D26-D31. https://doi. org/10.1093/nar/gkx1094

Boes M (2001) Role of natural and immune IgM antibodies in immune responses. Mol Immunol 37:1141-1149. https://doi.org/10.1016/ S0161-5890(01)00025-6

Borchers K, Frölich K (1997) Antibodies against Equine Herpesviruses in free-ranging mountain zebras from Namibia. J Wildl Dis 33:812-817. https://doi.org/10.7589/0090-3558-33.4.812

Borghesi J, Mario LC, Rodrigues MN, Favaron PO, Miglino MA (2014) Immunoglobulin transport during gestation in domestic animals and humans-a review. Open J Anim Sci 04:323-336. https://doi.org/10.4236/ojas.2014.45041

Bowden TJ (2008) Modulation of the immune system of fish by their environment. Fish Shellfish Immunol 25:373-383. https://doi. org/10.1016/j.fsi.2008.03.017
Boyd L (1986) Behavior problems of equids in zoos. Vet Clin $\mathrm{N}$ Am Equine Pract 2:653-664. https://doi.org/10.1016/S0749 $-0739(17) 30713-7$

Budzyńska M (2002) The evaluation of some physiological indices of Arabian mares during pregnancy and lactation. J Anim Feed Sci 11(2):289-298. https://doi.org/10.22358/jafs/67813/2002

Buehler DM, Piersma T, Irene Tieleman B (2008) Captive and free-living red knots Calidris canutus exhibit differences in non-induced immunity that suggest different immune strategies in different environments. J Avian Biol 39:560-566. https://doi.org/10.111 1/j.0908-8857.2008.04408.x

Costantini D, Seeber PA, Soilemetzidou S-E, Azab W, Bohner J, Buuveibaatar B, Czirják GÁ, East ML, Greunz EM, Kaczensky P, Lamglait B, Melzheimer J, Uiseb K, Ortega A, Osterrieder N, Sandgreen D-M, Simon M, Walzer C, Greenwood AD (2018) Physiological costs of infection: herpesvirus replication is linked to blood oxidative stress in equids. Sci Rep 8:10347. https://doi. org/10.1038/s41598-018-28688-0

Cray C, Belgrave RL (2014) Haptoglobin quantitation in serum samples from clinically normal and clinically abnormal horses. J Equine Vet Sci 34:337-340. https://doi.org/10.1016/j.jevs.2013.05.007

Cray C, Zaias J, Altman NH (2009) Acute phase response in animals: a review. Comp Med 59:517-526

Cray C, Arheart KL, Hunt M, Clauss T, Leppert LL, Roberts K, McCulloch SD, Goldstein JD, Gonzalez C, Sweeney J, Stone R, Fair PA, Bossart GD (2013) Acute phase protein quantitation in serum samples from healthy Atlantic bottlenose dolphins (Tursiops truncatus). J Vet Diagnostic Investig 25:107-111. https://doi. org/10.1177/1040638712467986

East ML, Otto E, Helms J, Thierer D, Cable J, Hofer H (2015) Does lactation lead to resource allocation trade-offs in the spotted hyaena? Behav Ecol Sociobiol 69:805-814. https://doi.org/10.1007/s0026 5-015-1897-x

Ehlers B, Borchers K, Grund C, Frölich K, Ludwig H, Buhk HJ (1999) Detection of new DNA polymerase genes of known and potentially novel herpesviruses by PCR with degenerate and deoxyinosine-substituted primers. Virus Genes 18:211-220. https://doi. org/10.1023/A:1008064118057

Ewenson E, Zann R, Flannery G (2001) Body condition and immune response in wild zebra finches: effects of capture, confinement and captive-rearing. Naturwissenschaften 88:391-394. https://doi. org/10.1007/s001140100250

Fair PA, Schaefer AM, Houser DS, Bossart GD, Romano TA, Champagne CD, Stott JL, Rice CD, White N, Reif JS (2017) The environment as a driver of immune and endocrine responses in dolphins (Tursiops truncatus). PLoS One 12:e176202. https://doi. org/10.1371/journal.pone.0176202

Flies AS, Mansfield LS, Grant CK, Weldele ML, Holekamp KE (2015) Markedly elevated antibody responses in wild versus captive spotted hyenas show that environmental and ecological factors are important modulators of immunity. PLoS One 10:e0137679. https ://doi.org/10.1371/journal.pone.0137679

Fox J, Weisberg S (2011) An R companion to applied regression, 2nd edition. ed. Thousand Oaks, CA

French SS, DeNardo DF, Moore MC (2007) Trade-Offs between the reproductive and immune systems: facultative responses to resources or obligate responses to reproduction? Am Nat 170:7989. https://doi.org/10.1086/518569

Guevara L, Abdelgawad A, Onzere C, Greenwood AD, Davidson Z, Bishop R, Mutinda M (2018) Seroprevalence of Equine Herpesviruses 1 and 9 (EHV-1 and EHV-9) in wild Grévy's zebra (Equus grevyi) in Kenya. J Wildl Dis. https://doi.org/10.7589/2018-01-003

Heinrich SK, Hofer H, Courtiol A, Melzheimer J, Dehnhard M, Czirják GÁ, Wachter B (2017) Cheetahs have a stronger constitutive innate immunity than leopards. Sci Rep 7:44837. https://doi. org/10.1038/srep44837 
Hothorn T, Bretz F, Westfall P (2008) Simultaneous inference in general parametric models. Biometrical J 50:346-363. https://doi. org/10.1002/bimj.200810425

IUCN, 2017. Equus quagga (Burchell's zebra) [WWW Document]. http://www.iucnredlist.org/details/41013/0. Accessed 6 Jun 2017

Janeway C, Travers P, Walport M, Shlomchick M (2001) Immunobiology, 5th edn. Garland Publishing, New York

Kleiboeker SB, Schommer SK, Johnson PJ, Ehlers B, Turnquist SE, Boucher M, Kreeger JM (2016) Association of two newly recognized herpesviruses with interstitial pneumonia in donkeys. J Vet Diagn Invest 14(4):273-280. https://doi.org/10.1177/10406 3870201400401

Lee KA (2006) Linking immune defenses and life history at the levels of the individual and the species. Integr Comp Biol 46:1000 1015. https://doi.org/10.1093/icb/ic1049

Lloyd S (1983) Effect of pregnancy and lactation upon infection. Vet Immunol Immunopathol 4:153-176. https://doi.org/10.1016/01652427(83)90057-0

Lochmiller RL, Deerenberg C (2014) Trade offs in evolutionary immunology Just what is the cost of immunity. Oikos 88:87-98. https:// doi.org/10.1034/j.1600-0706.2000.880110.x

Marenzoni M, Stefanetti V, Danzetta ML, Timoney PJ (2015) Gammaherpesvirus infections in equids: a review. Vet Med Res Rep 6:91-101. https://doi.org/10.2147/VMRR.S39473

Martin LB, Weil ZM, Nelson RJ (2006) Refining approaches and diversifying directions in ecoimmunology. Integr Comp Biol 46:1030 1039. https://doi.org/10.1093/icb/icl039

Mason GJ (2010) Species differences in responses to captivity: stress, welfare and the comparative method. Trends Ecol Evol 25:713721. https://doi.org/10.1016/j.tree.2010.08.011

Mellor E, McDonald Kinkaid H, Mason G (2018) Phylogenetic comparative methods: harnessing the power of species diversity to investigate welfare issues in captive wild animals. Zoo Biol. https ://doi.org/10.1002/zoo.21427

Moffett A, Loke C (2006) Immunology of placentation in eutherian mammals. Nat Rev Immunol 6:584-594. https://doi.org/10.1038/ nri1897

Morgan KN, Tromborg CT (2007) Sources of stress in captivity. Appl Anim Behav Sci 102:262-302. https://doi.org/10.1016/j.appla nim.2006.05.032

Pap PL, Czirják GÁ, Vágási CI, Barta Z, Hasselquist D (2010) Sexual dimorphism in immune function changes during the annual cycle in house sparrows. Naturwissenschaften 97:891-901. https://doi. org/10.1007/s00114-010-0706-7

Pap PL, Vágási CI, Vincze O, Osváth G, Veres-Szászka J, Czirják GÁ (2015) Physiological pace of life: the link between constitutive immunity, developmental period, and metabolic rate in European birds. Oecologia 177:147-158. https://doi.org/10.1007/s0044 2-014-3108-2

Peck HE, Costa DP, Crocker DE (2016) Body reserves influence allocation to immune responses in capital breeding female northern elephant seals. Funct Ecol 30:389-397. https://doi. org/10.1111/1365-2435.12504

Pedersen AB, Babayan SA (2011) Wild immunology. Mol Ecol 20:872-880. https://doi.org/10.1111/j.1365-294X.2010.04938.x

Pepys MB, Baltz ML, Tennent GA, Kent J, Ousey J, Rossdale PD (1989) Serum amyloid A protein (SAA) in horses: objective measurement of the acute phase response. Equine Vet J 21:106-109. https://doi.org/10.1111/j.2042-3306.1989.tb02108.x

R Development Core Team (2016) R: a language and environment for statistical computing. Austria, Vienna

Rauw WM (2012) Immune response from a resource allocation perspective. Front Genet 3:267. https://doi.org/10.3389/fgene .2012 .00267
Rowe M, Czirják GÁ, Lifjeld JT, Giraudeau M (2013) Lysozyme-associated bactericidal activity in the ejaculate of a wild passerine. Biol J Linn Soc 109:92-100. https://doi.org/10.1111/bij.12044

Ruoss S, Becker NI, Otto MS, Czirják GÁ, Encarnação JA (2019) Effect of sex and reproductive status on the immunity of the temperate bat Myotis daubentonii. Mamm Biol 94:120-126. https:// doi.org/10.1016/j.mambio.2018.05.010

Sandland GJ, Minchella DJ (2003) Costs of immune defense: an enigma wrapped in an environmental cloak? Trends Parasitol 19:571-574. https://doi.org/10.1016/j.pt.2003.10.006

Schulte-Hostedde AI, Mastromonaco GF (2015) Integrating evolution in the management of captive zoo populations. Evol Appl 8:413-422. https://doi.org/10.1111/eva.12258

Seeber PA, Soilemetzidou SE, East ML, Walzer C, Greenwood AD (2017) Equine behavioral enrichment toys as tools for non-invasive recovery of viral and host DNA. Zoo Biol. 36:341-344. https ://doi.org/10.1002/zoo.21380

Seeber P, Quintard B, Sicks F, Dehnhard M, Greenwood A, Franz M (2018a) Environmental stressors may cause equine herpesvirus reactivation in captive Grévy's zebras (Equus grevyi). PeerJ 6:e5422. https://doi.org/10.7717/peerj.5422

Seeber PA, Franz M, Dehnhard M, Ganswindt A, Greenwood AD, East ML (2018b) Plains zebra (Equus quagga) adrenocortical activity increases during times of large aggregations in the Serengeti ecosystem. Horm Behav 102:1-9. https://doi.org/10.1016/j.yhbeh.2018.04.005

Seeber PA, Dayaram A, Sicks F, Osterrieder N, Franz M, Greenwood AD (2019) Noninvasive detection of equid herpesviruses in fecal samples. Appl Environ Microbiol 85:1-8. https://doi.org/10.1128/ AEM.02234-18

Sheldon BC, Verhulst S (1996) Ecological immunology: costly parasite defences and trade-offs in evolutionary ecology. Trends Ecol Evol 11:317-321. https://doi.org/10.1016/0169-5347(96)10039-2

Svansson V, Roelse M, Ólafsdóttir G, Thorsteinsdóttir L, Torfason EG, Torsteinsdóttir S (2009) Immune response against equine gammaherpesvirus in Icelandic horses. Vet Microbiol 137:363-368. https://doi.org/10.1016/j.vetmic.2009.01.020

Tian J, Courtiol A, Schneeberger K, Greenwood AD, Czirják GÁ (2015) Circulating white blood cell counts in captive and wild rodents are influenced by body mass rather than testes mass, a correlate of mating promiscuity. Funct Ecol 29:823-829. https:// doi.org/10.1111/1365-2435.12394

Tung J, Barreiro LB, Johnson ZP, Hansen KD, Michopoulos V, Toufexis D, Michelini K, Wilson ME, Gilad Y (2012) Social environment is associated with gene regulatory variation in the rhesus macaque immune system. Proc Natl Acad Sci 109:6490-6495. https://doi.org/10.1073/pnas.1202734109

Veronesi MC, Dall P, Gloria A, Servida F, Sala E, Robbe D (2014) $\mathrm{IgG}, \mathrm{IgA}$, and lysozyme in Martina Franca donkey jennies and their foals. Theriogenology 81:825-831. https://doi.org/10.1016/j. theriogenology.2013.12.018

Viney M, Riley EM (2017) The immunology of wild rodents: current status and future prospects. Front Immunol 8:1481. https://doi. org/10.3389/fimmu.2017.01481

Wambwa EN, Ogara WO, Mudakha D (2004) A comparative study of gastrointestinal parasites between ranched and free ranging Burchell's zebra (Equus burchelli antiquorum) in Isiolo district, Kenya. J Vet Sci (Suwon-si, Korea) 5:215-220. https://doi.org/1 0.1111/j.1461-0248.2009.01359.x

White DW, Suzanne Beard R, Barton ES (2012) Immune modulation during latent herpesvirus infection. Immunol Rev 245:189-208. https://doi.org/10.1111/j.1600-065X.2011.01074.x

Publisher's Note Springer Nature remains neutral with regard tojurisdictional claims in published maps and institutional affiliations. 